\title{
Attitudes and Beliefs of African-Americans Toward Genetics, Genetic Testing, and Sickle Cell Disease Education and Awareness
}

\author{
Katie A. Long • Stephen B. Thomas • Robin E. Grubs • \\ Elizabeth A. Gettig • Lakshmanan Krishnamurti
}

Received: 15 October 2010 / Accepted: 23 June 2011

(C) National Society of Genetic Counselors, Inc. 2011

\begin{abstract}
Research among African-Americans indicates this population perceives sickle cell (SCD) to be a serious disease and sickle cell trait (SCT) screening an important intervention. However, studies have consistently demonstrated a lower than desired uptake of SCD education, inadequate knowledge regarding personal and family trait status, and a low perceived susceptibility of giving birth to a child with the disease. We examined general attitudes and beliefs regarding genetics and genetic testing including prenatal testing and newborn screening; we used this information as the foundation to more specifically assess attitudes and beliefs regarding SCD and perceived barriers to SCD education and awareness. Thirty-five AfricanAmerican adult men and women participated in one of four focus groups. Thematic analysis identified that both prenatal testing and newborn screening are acceptable forms of genetic testing. Based largely on their personal
\end{abstract}

K. A. Long $\cdot$ R. E. Grubs $\cdot$ E. A. Gettig

Department of Human Genetics, University of Pittsburgh,

Pittsburgh, PA, USA

S. B. Thomas

Department of Health Services Administration,

University of Maryland,

College Park, MD, USA

L. Krishnamurti

Division of Hematology, Oncology, and Bone Marrow Transplant, Children's Hospital of Pittsburgh,

Pittsburgh, PA, USA

K. A. Long $(\square)$

Children's Hospital of Pittsburgh,

One Children's Hospital Drive, 4401 Penn Ave.,

Faculty Pavilion Suite 1200,

Pittsburgh, PA 15224, USA

e-mail: katie.long@chp.edu experiences, participants possessed an understanding of the natural progression of SCD but had a limited understanding of the inheritance and probable risk of giving birth to a child with the disease. Barriers to education and greater awareness of SCD were classified as personal, familial, and societal. Community based interventions focused on sharing the stories of individuals with first-hand experiences with SCD should be considered.

Keywords Sickle cell disease $\cdot$ African-American $\cdot$ Health belief - Qualitative research - Thematic analysis - Genetic testing $\cdot$ Genetic counseling

\section{Introduction}

Sickle cell disease (SCD) is an autosomal recessive genetic condition that results in red blood cells with a characteristic sickle shape. Mutations in the $H B B$ gene are responsible for causing the known forms of SCD including hemoglobin SS disease, SC disease, SD disease, and the two forms of sickle beta-thalassemia, $\mathrm{HbS} \beta+$ and $\mathrm{HbS} \beta_{0}$ (Richer and Chudley 2005; Wethers 2000a, b; Wilson et al. 2003). Hemoglobin $\mathrm{S}$ and other abnormal beta-globin chains create a brittle consistency that is easily lysed and more capable of adhering to the endothelial cells of the vascular system. The pathogenic process begins when the sickled hemoglobin is polymerized as a result of deoxygenation leaving the red blood cell to become dehydrated and deformed. It is this red blood cell that can adhere to the vascular endothelium. As a result, individuals with SCD can experience hemolysis, anemia, pain episodes, swelling, and vascular occlusion potentially leading to ischemic attacks and organ damage (Richer and Chudley 2005; Wethers 2000a, b; Wilson et al. 2003). 
Sickle cell disease is a pan-ethnic condition with the highest prevalence among those of African, Mediterranean, Middle Eastern, Indian, Caribbean, and Central and South American descent (Wethers 2000a, b; Wilson et al. 2003). Every 1 in 12 African-Americans has sickle cell trait (SCT), and the disease affects 1 in 375 African-Americans (Richer and Chudley 2005; Wethers 2000a, b).

The first statewide newborn screening program for SCD was initiated in New York in 1975. However, it was not until 1986 that studies were published demonstrating the benefit of prophylactic penicillin to prevent infection and early death in children with SCD. In 1996, the American Academy of Pediatrics recommended every state implement targeted newborn screening for hemoglobinopathies and currently, all states screen for this class of conditions (Olney 2000). Newborn screening for hemoglobinopathies including SCD is performed by isoelectric focusing in the majority of screening programs; however, some states utilize high performance liquid chromatography in conjunction with isoelectric focusing. The purpose of newborn screening for SCD is to identify affected individuals but due to test methodology, SCT can be detected as well. Because identification of SCT is not the objective of screening, some laboratories do not report these results. When a diagnosis of SCD is made, prophylactic penicillin is recommended to be administered by 2 to 3 months of age in order to reduce the incidence of pneumococcal sepsis (Pass et al. 2000).

\section{Uptake of Sickle Cell Disease Education and Genetic} Counseling Following Identification of Trait

Few states have aggressive follow-up programs or staff devoted to SCT follow-up after the identification of trait by newborn screening. However, those programs designed to offer genetic counseling and follow-up have met with limited success and uptake by parents and families. In a 2000 report from the National Newborn Screening and Genetics Resource Center (2009), only $15 \%$ of the 50,491 infants identified with SCT had confirmatory testing, and the resulting uptake of family counseling and testing is unknown (Kladny et al. 2005).

A 2005 study by Kladny and colleagues examined SCT follow-up and genetic counseling pre and post implementation of an intensive follow-up protocol for infants with an abnormal hemoglobinopathy trait identified by newborn screening. Between 1997 and 2002, families were notified of their infant's SCT status by mail and offered genetic counseling. Only $5.3 \%$ of those families received genetic counseling by telephone, and $2 \%$ underwent extended family member testing. In 2003 an intensive follow-up protocol was implemented including letters, telephone calls, educational videos, and the possibility of providing genetic counseling over the phone or in person. In 9 months following the start of this protocol, $52 \%$ of families were reached by telephone. Of these families, 92\% accepted genetic counseling by telephone and $12 \%$ scheduled an appointment for genetic counseling in person. This intensive follow-up significantly improved acceptance of SCD genetic counseling. However, few states support this type of program. In a 2009 report from the National Newborn Screening and Genetics Resource Center (2009), only 12 of 50 states $(24 \%)$ have what they label as an "aggressive follow-up protocol" for SCT. Without this type of follow-up in place, the uptake of SCD education and genetic counseling remains lower than desired even among those families who have a child identified to have SCT. There still remains a significant portion of parents and families who do not receive information about the inheritance of SCD, and it is assumed that many do not understand the risks to future children and grandchildren.

\section{Knowledge and Perception of Sickle Cell Disease}

A limited number of studies have been conducted to examine African-Americans' knowledge and perception of SCD, SCT, personal and family trait status, and newborn screening for SCD. These studies have consistently demonstrated a significant lack of awareness regarding the difference between disease and trait status and how trait status increases the chance to have a child with disease (Acharya et al. 2009; Gustafson et al. 2007; Kladny et al. 2005; Midence et al. 1994; Treadwell et al. 2006; Wright et al. 1994). A 2006 study by Treadwell and colleagues examined knowledge and misconceptions about the disease among African-American community members in a large metropolitan area. Survey results determined only $15.9 \%$ of individuals knew their trait status and of those, 53\% learned their trait status through discussion with family members. Respondents who received information from friends and family were three times more likely to know their trait status, demonstrating the potential benefit of family discussions about sickle cell.

Similarly, Acharya and colleagues (2009) found that among parents with a child identified with SCD or SCT and parents known to have SCT, the majority were knowledgeable of their own SCT status. Only $6 \%$ of participants surveyed did not know their SCT status. The majority of participants learned their SCT status during prenatal screening or positive newborn screening, and those with an affected child cited pediatricians and SCD clinic staff as the most common sources of sickle cell information. Parents who did not have a child with SCD cited family members as their most common source for this type of information. Collectively, participants had a significant misunderstanding of sickle cell inheritance. However, 
parents of an affected child who had an opportunity to meet with SCD physicians and clinic staff had a greater understanding of inheritance when compared to those without an affected child, highlighting the value of personal conversations with healthcare professionals.

Given the presence of significant misconceptions, some research has been done to elucidate potential barriers to the understanding of SCD. In focus groups conducted by Treadwell and colleagues (2006), participants discussed follow-up counseling for SCT detected by newborn screening, described their understanding of SCD, and suggested possible solutions for poor follow-up rates for SCT counseling. Common themes among community members who participated in these focus groups included limited visibility of SCD and SCT and the need to use media to promote awareness. Participants discussed the stigma associated with any type of disease in the AfricanAmerican community and the need for health care professionals to have compassion and cultural sensitivity when discussing sickle cell. In contrast, Acharya and colleagues (2009) found that among adults with SCT all either disagreed or strongly disagreed with the statement "I worry about people discriminating against me." These researchers were unable to demonstrate significant stigma attached to SCT.

Gustafson and colleagues (2007) examined AfricanAmericans' knowledge and perceptions of sickle cell screening and counseling by surveying health beliefs among African-American women. The survey design and analysis were based on the Health Belief Model, which is grounded in the idea that a health prevention or screening behavior will only occur when an individual believes the health concern is serious enough to warrant screening, he or she is at risk of the disorder, there is a benefit to pursuing the screening and the barriers to pursuing screening are low (Janz and Becker 1984). The study found among AfricanAmerican women of childbearing age there is a good understanding of the severity of SCD, high perceived benefit of genetic testing and counseling, and low perceived barriers to obtaining this testing.

As with previous research however, the results indicated a low perceived personal risk to have a child with SCD. The authors suggested that a low perceived susceptibility is one potential explanation for the poor uptake of genetic testing and counseling. Although perceived susceptibility did not correlate with knowledge of SCD, participants with an understanding of recessive inheritance did demonstrate a higher perceived susceptibility to have a child with SCD. Additionally, an increased level of average SCD knowledge was found to be significantly related to a high perceived severity of SCT and to the perceived benefit of SCT screening. The authors suggested that participants with personal experiences or relationships with individuals or families affected by SCD will know more about SCD and its severity which may cause them to believe screening is more beneficial for reproductive planning. Based on their findings, the authors recommended that additional research be conducted to examine why African American women do not believe they are at risk to have a child with SCD.

\section{Attitudes Toward Genetic Testing}

The high degree of perceived benefit from genetic testing and counseling for SCD identified by Gustafson and colleagues (2007) is of significance given that several research studies examining the general attitudes and beliefs of African-Americans toward genetic testing have found participants hold both serious concerns and positive beliefs about the benefits of testing. Studies conducted among individuals in clinical, educational, and community settings consistently demonstrate that minority participants describe considerable risks associated with genetic testing including, but not limited to, the possible misuse of genetic information for the purpose of racial discrimination. However, minorities also describe benefits of genetic testing for prevention of disease (Catz et al. 2005; Kessler et al. 2005; Laskey et al. 2003; Zimmerman et al. 2006).

Catz and colleagues (2005) examined attitudes toward genetic topics among minority populations recruited from community health centers. Of the 55 participants, 15 were African-American and comprised two focus groups. The greatest percentage $(35 \%)$ of minority participants could not provide any information when asked what they had heard about genetic testing. When asked more specifically about newborn screening, $45 \%$ were not aware that it is routinely performed. The most commonly mentioned genetic test by African-Americans was amniocentesis to detect abnormalities in the fetus. The majority of minority participants articulated the main benefit of genetic testing to be prevention of, or preparation for disease. However, participants also listed concerns for the unethical use of testing, anxiety from test results, and false reassurance from negative results. Newborn screening was viewed as a method to prepare for a child's health problems. However, African-Americans and other minority participants expressed practical concerns about the outcome of genetic testing through newborn screening including apprehension about insurability, financial burdens, parenting responsibilities for a sick child, and the potential to test positive for a disease with no cure.

In contrast to the study by Catz and colleagues (2005) which examined attitudes toward genetic testing among minorities with a range of educational levels, Laskey and colleagues (2003) pursued similar questioning among African-American college students in a premedical program. These undergraduates also stated that genetic testing 
could benefit individuals/families by allowing for prevention or preparation. However, the group's overall concerns about the risks of genetic testing were more theoretical in comparison to the responses obtained by Catz and colleagues. Concerns about genetic testing included risk of genetic discrimination, increasing abortion rates, eugenics, and breach of confidentiality.

\section{Sickle Cell Disease and Genetic Discrimination}

Genetic discrimination is a well documented fear among those considering genetic testing, but few studies have been performed examining the current prevalence of insurance, employment, or other forms of discrimination among those with SCD or SCT. As described in a report by The New York State Task Force on Life and the Law (2000), in 1971 a national, government supported program for sickle cell disease was established. As a result, several states enacted laws mandating African-Americans undergo sickle cell screening, and in some states, marriage licenses and school attendance could be denied based on refusal of screening. Physician education on the topic was poor, and the rapid rush to screen increased the opportunity for misunderstandings about the disease. The distinction between affected and trait status was not clearly articulated by screening programs, and initial testing methodology did not distinguish between SCD and SCT. Additionally, inaccurate information claiming shortened life expectancy among those with SCT was perpetuated by some medical reports. These errors led to health and life insurance discrimination, as well as, employment discrimination and perceptions by some in the AfricanAmerican public that screening programs were eugenic in nature. Efforts were made to correct program mistakes, and the 1980s brought revision of state screening laws, more reliable testing methods, and improved education programs.

More recently, Kass and colleagues (2007) specifically compared the health insurance experiences, attitudes, and beliefs of individuals with genetic conditions to those with or at risk for other serious medical conditions in order to better define the extent, if any, of insurance discrimination against those with genetic conditions. Ninety-nine of 597 interviews were with adults with SCD or parents of children with SCD. Results indicated that those with SCD and cystic fibrosis were two times as likely to report having been denied health insurance compared to those with non-genetic conditions adjusting for age, income, marital status, race, and employment status. Additionally, when transitioning from being uninsured to obtaining insurance, study participants with SCD or HIV were least likely to report having a choice of insurance plans. These results possibly indicate that those with a diagnosis of SCD may be experiencing greater rates of genetic discrimination in the form of health insurance discrimination.
Purpose of the Present Study

It is generally understood that past experiences, attitudes, and beliefs influence the way individuals approach new information, learning, and decision-making (Catz et al. 2005). As described previously, research among AfricanAmericans indicates this population perceives SCD to be a serious disease and SCT screening an important intervention. However, studies have consistently demonstrated a lower than desired uptake of SCD education, inadequate knowledge regarding personal and family trait status, and a low perceived susceptibility of giving birth to a future child with the disease. We have chosen to examine general attitudes and beliefs regarding genetics and genetic testing including prenatal testing and newborn screening among a unique sample of African-American adults and use this information as the foundation to more specifically assess attitudes and beliefs regarding SCD and perceived barriers to SCD education and awareness.

\section{Methods}

\section{Participants}

Study participants included African-American men and women 18 years and older recruited from the Healthy Black Family Project (HBFP), a community based health promotion and disease prevention program located in racially segregated neighborhoods characterized by poverty and chronic diseases. Participants were invited to participate in an anonymous survey and focus group. The study and all materials were approved by the University of Pittsburgh Institutional Review Board. The HBFP was established in 2005 by the Research Center of Excellence in Minority Health Disparities (RCEMHD) at the Graduate School of Public Health, University of Pittsburgh. A detailed description of the HBFP population $(N=7,000)$ and intervention components are described elsewhere (Thomas and Quinn 2008). Members typically reside in the predominately African-American communities of Pittsburgh which surround the Kingsley Association, a community recreation and human service center which serves as the HBFP headquarters (Vogel et al. 2007). Study participants were recruited using culturally tailored flyers distributed at the Kingsley Association and in monthly HBFP membership mailings. Study participants were also recruited from the Minority Research Recruitment Database (MRRD) established by the RCEMHD using a telephone script. The MRRD is a voluntary database composed of individuals who provided informed consent to receive information about research including clinical trials (Vogel et al. 2007). In the present study, at the time of recruitment, participants 
were notified that focus groups would require approximately $2 \mathrm{~h}$ of time, and they would receive refreshments and a $\$ 25$ gift card to a local grocery store. Participants were not required to sign a consent form by the Institutional Review Board but were informed about the nature of the study via an introductory script.

\section{Instrumentation and Procedures}

Four focus groups were conducted at the Kingsley Association. Each group was held in a community room, and participants sat together at a common table with the focus group moderator for discussion. Audio recordings of the focus groups were collected for later transcription and participants chose an alias to use during discussion. There was one moderator and one assistant to the moderator who conducted each of the four focus groups. Both the moderator and assistant to the moderator were genetic counseling graduate student researchers with the HBFP and had the opportunity to previously interact with several of the focus group participants during other HBFP activities. Focus groups were conducted according to a moderator's guide (See Appendix) and notes of the discussion were taken by an assistant to the moderator.

Participants were asked to complete an anonymous survey designed to characterize demographics and experience with SCD and SCT. The survey consisted of 19 questions and took approximately $10 \mathrm{~min}$ to complete (See Appendix). Section one contained demographic questions and questions regarding genetics knowledge, personal health, and health insurance status. This section of the survey is part of a standard survey previously utilized for other HBFP activities and research studies. Section two was comprised of questions regarding the participants' familiarity with SCD and SCT and knowledge of personal and family trait status.

\section{Data Analysis}

Survey results were analyzed using descriptive statistics. Frequencies, means, medians, and ranges were calculated, as appropriate for major survey items.

Focus group audio tapes were transcribed by an employee of the RCEMHD who was not directly involved in this research study. Transcription adhered to participants' grammar, pauses, place holders, and unfinished sentences. Each transcript was read twice by a coder to gain familiarity with the data, and the audio tapes were listened to once while reading each transcript to ensure accuracy. The coder, who was also the moderator for this study, analyzed all data; however, transcripts and coding were reviewed regularly with members of the research team to attempt to limit bias.
Transcripts were uploaded into QSR NUDIST VIVO ${ }^{\circledR}$, a software program designed to manage and facilitate analysis of qualitative data. Transcripts were analyzed using qualitative thematic analysis with an inductive approach utilizing both interpretive and explicit themes (Beeson 1997; Braun and Clarke 2006; Sandelowski 2000). Codes were generated to reflect the participants' views and opinions and revised throughout the process in order to better refine and capture participants' beliefs. Each transcript was coded for interesting features and data were collated for each code. The codes were then searched for common themes and comparison of codes across transcripts enabled the identification of themes summarizing the views of multiple individuals. The coder used these themes to go back and determine if participant responses across transcripts were accurately represented by these themes.

Based on the data analysis, the qualitative data was organized into five main topics: attitudes and beliefs about genetics, attitudes and beliefs about prenatal testing, attitudes and beliefs about newborn screening, attitudes and beliefs about sickle cell, and barriers to education and awareness of sickle cell. Each of these main topics was further broken down into sub-topics as they emerged from analysis of the data. Specific themes within each of these sub-topics were identified from the participants' responses. In some cases, a particular theme was consistently expressed across multiple sub-topics.

\section{Results}

\section{Survey Responses}

Thirty-five individuals completed the pre-discussion survey and participated in one of four focus groups. The four groups consisted, respectively, of 11 females; 6 females; 8 females and 2 males; and 7 females and 1 male. Table 1 contains a summary of participant demographics. The mean age of participants was 53 years (median $=57$ years; range: 26-77 years). Of these individuals, the vast majority were female (91\%) and African-American (91\%). However, all individuals who participated in the focus groups were members of the HBFP and self-identified as AfricanAmerican or mixed ancestry including African-American heritage. Approximately $82 \%$ of participants had children. The most prevalent income level was between $\$ 20,000$ and $35,000(32 \%)$, and the most prevalent educational level was $1-3$ years of college or technical school $(40 \%)$. At the time of data collection, the US poverty threshold for a family of four was approximately $\$ 19,806$ and the poverty level for a family of two was approximately $\$ 13,078$ (US Census Bureau 2005). 
When asked about personal health, 57\% indicated they are in good health, $54 \%$ believed themselves to be overweight, and $17 \%$ were smokers (Table 1). Approximately $97 \%$ reported having a form of health insurance, $57 \%$ had one personal physician, and $17 \%$ indicated they could not go to the doctor within the last year because of cost.

Participants' ratings of genetics knowledge and familiarity with SCT and SCD revealed that a majority of individuals believe they have a fair knowledge of genetics (47\%) and a majority indicated they know someone with SCT (64\%) and someone with SCD (64\%) (Table 2). Of those individuals who reported knowing someone with SCT or SCD, $20 \%$ also indicated knowing an individual who was found to have trait or disease by newborn screening. Forty-two percent of participants acknowledged knowing their own SCT status. For those individuals with a spouse or partner $(n=26), 26 \%$ reported knowing that individual's SCT status. Among participants with children $(n=28)$, $40 \%$ indicated knowing their child or children's SCT status.

\section{Themes in Focus Group Responses}

Themes were identified by collective analysis of all four focus group sessions (Krueger and Casey 2000). All themes were identified in each of the four groups. Individual comments from focus group participants were selected to illustrate the theme described.

Topic: Attitudes and Beliefs about Genetics

Sub-Topic: Primary Source for Information about Genetics

\section{Familiarity}

Participants identified the following primary resource(s) for obtaining information about genetics: high school and college coursework, experiences on the job or as a participant in research studies, physicians, the media (internet, newspaper, magazines, and television programs including those for entertainment, health and science information, and news), family, and friends. In general, participants valued a particular individual or source as a resource because of an association with the medical profession and a feeling of familiarity and trust. The importance of family and friends as primary resources for health/genetic information was highlighted over the course of focus group conversations and is captured in the following quotes:

I think that is true that the black community will have someone that works at a hospital or has been at a
Table 1 Demographics of focus group participants

\begin{tabular}{|c|c|c|}
\hline Demographic variable & $\%$ & $n$ \\
\hline \multicolumn{3}{|l|}{$\operatorname{Sex}(n=35)$} \\
\hline Male & 8.6 & 3 \\
\hline Female & 91.4 & 32 \\
\hline \multicolumn{3}{|l|}{ Ethnicity $(n=35)$} \\
\hline Hispanic & 0.0 & 0 \\
\hline Not Hispanic & 100.0 & 35 \\
\hline \multicolumn{3}{|l|}{ Race $(n=35)$} \\
\hline White & 0.0 & 0 \\
\hline Black or African-American & 91.4 & 32 \\
\hline Asian & 0.0 & 0 \\
\hline Native Hawaiian or Pacific Islander & 0.0 & 0 \\
\hline American Indian, Alaska Native & 0.0 & 0 \\
\hline Other & 8.6 & 3 \\
\hline \multicolumn{3}{|l|}{ Total Household Income $(n=34)$} \\
\hline Less than $\$ 10,000$ & 8.8 & 3 \\
\hline$\$ 10,000-\$ 20,000$ & 23.5 & 8 \\
\hline$\$ 20,001-\$ 35,000$ & 32.4 & 11 \\
\hline$\$ 35,001-\$ 50,000$ & 17.6 & 6 \\
\hline$\$ 50,001-\$ 75,000$ & 11.8 & 4 \\
\hline Greater than $\$ 75,000$ & 5.9 & 2 \\
\hline \multicolumn{3}{|l|}{ Education $(n=35)$} \\
\hline Elementary & 0.0 & 0 \\
\hline Some high school & 0.0 & 0 \\
\hline High school graduate & 28.6 & 10 \\
\hline Some college or technical school & 40.0 & 14 \\
\hline College graduate or post graduate & 17.1 & 6 \\
\hline Masters or $\mathrm{PhD}$ & 14.3 & 5 \\
\hline \multicolumn{3}{|l|}{ Personal Health Rating $(n=35)$} \\
\hline Excellent & 2.9 & 1 \\
\hline Very Good & 11.4 & 4 \\
\hline Good & 57.1 & 20 \\
\hline Fair & 25.7 & 9 \\
\hline Poor & 2.9 & 1 \\
\hline \multicolumn{3}{|l|}{ Personal Weight $(n=35)$} \\
\hline Underweight & 0.0 & 0 \\
\hline Healthy weight & 25.7 & 9 \\
\hline Overweight & 54.3 & 19 \\
\hline Obese & 20.0 & 7 \\
\hline \multicolumn{3}{|l|}{ Smoking Status $(n=35)$} \\
\hline Smoker & 17.1 & 6 \\
\hline Non-smoker & 82.9 & 29 \\
\hline \multicolumn{3}{|l|}{ Health Insurance Coverage $(n=35)$} \\
\hline Yes & 97.1 & 34 \\
\hline No & 2.9 & 1 \\
\hline Don’t know & 0.0 & 0 \\
\hline \multicolumn{3}{|l|}{ Personal Physician $(n=35)$} \\
\hline Yes, only one & 57.1 & 20 \\
\hline More than one & 40.0 & 14 \\
\hline No & 2.9 & 1 \\
\hline Don’t know & 0.0 & 0 \\
\hline \multicolumn{3}{|c|}{ Could Not See a Doctor due to Cost in Past Year $(n=35)$} \\
\hline Yes & 17.1 & 6 \\
\hline No & 82.9 & 29 \\
\hline Don’t know & 0.0 & 0 \\
\hline
\end{tabular}


Table 2 Focus group participants' experience with SCT and SCD

\begin{tabular}{|c|c|c|}
\hline Question & $\%$ & $n$ \\
\hline \multicolumn{3}{|c|}{ Knowledge of Genetics $(n=34)$} \\
\hline Excellent & 0.0 & 0 \\
\hline Very good & 8.8 & 3 \\
\hline Good & 38.2 & 13 \\
\hline Fair & 47.1 & 16 \\
\hline Poor & 5.9 & 2 \\
\hline \multicolumn{3}{|c|}{ Know Someone with SCT $(n=34)$} \\
\hline Yes & 64.7 & 22 \\
\hline No & 29.4 & 10 \\
\hline Don’t know & 5.9 & 2 \\
\hline \multicolumn{3}{|c|}{ Know Someone with SCD $(n=34)$} \\
\hline Yes & 64.7 & 22 \\
\hline No & 35.3 & 12 \\
\hline Don’t know & 0.0 & 0 \\
\hline \multicolumn{3}{|c|}{ Know Someone with SCT/SCD Identified by NBS $(n=34)$} \\
\hline Yes & 20.6 & 7 \\
\hline No & 64.7 & 22 \\
\hline Don’t know & 14.7 & 5 \\
\hline \multicolumn{3}{|c|}{ Knowledge of Personal SCT Status $(n=33)$} \\
\hline Yes & 42.4 & 14 \\
\hline No & 51.5 & 17 \\
\hline Don’t know & 6.1 & 2 \\
\hline \multicolumn{3}{|c|}{ Knowledge of Partner's SCT Status $(n=34)$} \\
\hline Yes & 20.6 & 7 \\
\hline No & 47.1 & 16 \\
\hline Don't know & 8.8 & 3 \\
\hline Not applicable & 23.5 & 8 \\
\hline \multicolumn{3}{|c|}{ Do You Have Children $(n=34)$} \\
\hline Yes & 82.3 & 28 \\
\hline No & 17.7 & 6 \\
\hline \multicolumn{3}{|c|}{ Knowledge of Child(ren)'s SCT Status $(n=27)$} \\
\hline Yes & 40.7 & 11 \\
\hline No & 55.6 & 15 \\
\hline Don't know & 3.7 & 1 \\
\hline
\end{tabular}

hospital for a long period of time and by that I mean my sister. She's 72 and we consider her the physician of the family. She has the PDR's [Physician's Desk Reference]. She's had a long experience with different illnesses and various things. My girlfriend she's worked at [Name of Hospital] for 25 years. When I want a specialist, I go to her but that is the way I think it happens. I think in the black community too, is that word of mouth. (Female)

I have a friend who is a physician's assistant, so every now and then we'll have like a woman session...We just get together every now and then for fun, but if there is anything we need to discuss, we ask her. (Female)

Sub-Topic: Definition of Genetics

\section{Inheritance}

The majority of individuals framed their understanding of genetics within the context of inheritance or "traveling down the line from generation to generation (Female)." There were some individuals who expressed a feeling that genetics is inescapable and that the health of past relatives has an effect on the current individual. Participants stated that "Inheritance is something that you are born with (Female)." and "...Your chromosomes, the $\mathrm{X}$ and Ys and then that determines certain elements (pause) if you have pre diagnosis history (Females)."

\section{Influenced by the Environment}

In contrast, there were participants who discussed how genetics can be shaped by environmental influences such as nutrition or how a mother's health can impact the outcome of a pregnancy.

\section{Defined by Scientific Terms}

It was common for study participants to use scientific or technical language such as "genes" and "DNA" to describe what genetics means to them. For example, as one participant stated, "When a child is born you get DNA from your parents, mother and father, and of course, your DNA is made up of all the past DNA and so you get half and half and you are who you are (Female)."

\section{Defined by the Media}

Some individuals described genetics by using popular media stories such as actor Michael J. Fox and stem cell research or media icon Oprah Winfrey and her tracing African heritage television series.

Topic: Attitudes and Beliefs about Prenatal Testing Sub-Topic: Definition of Prenatal Testing

Participants were able to correctly identify methods of and indications for prenatal testing. Within each focus group, there were individuals who had recently undergone prenatal testing or knew a friend or family member who had used prenatal testing. Participants identified ultrasound, amniocentesis, and viral studies as prenatal tests but did not explicitly use these words. A young 
woman referred to amniocentesis as "Being tested while you are pregnant with the long needle thing in your stomach." When identifying the types of prenatal tests available, participants' responses included testing for chromosomal conditions and single gene conditions. Individuals mentioned chromosome testing for Down syndrome most frequently. "I always think of chromosomal problems like Down syndrome and different problems that happen when you are pregnant and they can tell through prenatal testing (Female)." Attention was paid to SCD as a condition potentially tested for prenatally. "A lot of black kids have sickle cell; they might be able to detect that (Female)."

Sub-Topic: Potential Benefits of Prenatal Tests

\section{Value of Awareness}

Participants identified awareness as a benefit of having information about a pregnancy. Some believed this awareness would ultimately benefit the pregnancy and the baby while others discussed how this awareness would benefit the mother or the family. Several participants brought up the potential to correct a health problem that is identified prenatally: "Can't they do surgery while the baby is inside? They may find something in order to help the baby before they come out (Female)." Another participant stated prenatal testing was performed "to see what they can try and fix (Female)." Some individuals felt a health problem identified prenatally would allow the child to receive the appropriate care in the newborn period:

When you find out through prenatal testing something is wrong with that child and that child is born, then you know before you leave the hospital you can treat things so much differently-even different formulas and stuff. If you have a child with different types of diseases or something, you have to be very careful with [that child]. So if you know beforehand, then you don't make the mistake of hurting your own child from not knowing. (Female)

Awareness of a genetic condition during the prenatal period can also benefit the mother and the family. For some participants, awareness of a genetic condition allows the mother to be knowledgeable about possible recurrence and in select cases, make changes to lower the chance of recurrence. One woman described how parental awareness could help prevent spina bifida:

You could probably take that information to your next pregnancy. When you get pregnant again, if your body was too low with a certain vitamin or some type of nutrition you didn't have while you were pregnant, you could try to boost up on that before you get pregnant the next time so you won't have to face any difficulties or anything like that.

\section{Value of Choice}

Participants described choice as deciding between the option of abortion versus the option of continuation of a pregnancy when prenatal test results indicate the child would have a genetic or other debilitating condition. One woman felt that prenatal testing is performed "to see if there is any deformity in the child and then it gives the mother the right to say whether or not she wants to go full term." Another participant stated:

There also are certain diseases that run in certain races and so this kind of testing while the baby is still in utero can help identify them. For instance, Tay-Sachs is a disease that runs in certain groups of people and retardation and certain things like that. So if you know in the first term, then the doctor will say to you, you can make a decision at this time to go forth to go full term or you can terminate therapeutically at this point in time. So that's one very good reason why genetic testing in terms of prenatal is so important. (Female)

The value of choice in assessing whether or not an individual or couple will be able to care for a child with a genetic health condition was also identified.

...Sometimes too they can detect different birth defects before the person is full term to see if that person is able to take that child because the child is going to come deformed or something or maybe it's better medically to abort that child. (Female)

However, no participant mentioned specific social or financial situations which would cause a person to choose to terminate a pregnancy.

Sub-Topic: Potential Concerns or Risks of Prenatal Tests

\section{Miscarriage}

When asked to identify potential risks of prenatal testing, many made statements such as "You could have a miscarriage (Female)."

\section{Relationship Stress}

Participants cited concern about the impact of prenatal test results on family relationships. One participant characterized a 
possible interaction between a couple experiencing the process of prenatal testing:

[Prenatal testing is performed]...To see if there is any deformity in the child and then it gives the mother the right to say whether or not she wants to go full term because it may be traumatic to raise a child with special needs. So they [doctors] tell them to have a conference to decide what they want to do and sometimes doing that it will split up a family because mom says, 'I'm having my child I don't care what is wrong.' and dad is like, 'I'm not putting up with a child that has some special needs.' and so now you don't have a dad in the picture because he just felt he can't handle that kind of situation, and so a lot of women won't take it. They'll just say 'We'll find out what happens when the child gets here'. (Female)

\section{Personal Stress and Inability to Cope}

For some individuals, the detection of a health problem in a pregnancy could cause overwhelming stress, and they would prefer to be unaware of a problem throughout the course of the pregnancy. These individuals conveyed a sense of their personal limitations in managing stress.

I think if you know that you are not going to terminate the child and then you know there is something wrong with it, it could be real stressful for you, which would also be a problem for the baby. So if you are going to do it, I think you should decide before that if you do want to terminate it, but if you don't, I don't think you really should know ahead of time. (Female)

When I was trying to get pregnant, my husband and I, we had a very difficult time getting pregnant, so then they say once over 40 if you get pregnant you may be more at risk. So then they were going to test, and I said if I am not going to terminate, why would I want to test because it will just make me more anxious to have another miscarriage. (Female)

\section{Test Limitations}

Participants voiced concern about the limitations of prenatal tests and the stress which emerged from these limitations.

That is the only thing I didn't like about the prenatal testing. You had to wait and after the baby came out more testing was done, and none of the results were true because the sonograms weren't really efficient. They could see some degree of the child, but they are not really that great, so it was like I am more worrying. (Female)

Topic: Attitudes and Beliefs about Newborn Screening Sub-Topic: Knowledge of Newborn Screening

\section{Unaware}

When asked to describe newborn screening, the vast majority of focus group participants did not respond or made movements such as shoulder shrugging to indicate uncertainty. Common responses indicated a lack of awareness such as "Never heard the phrase [newborn screening]" and "So is this [newborn screening] something new? I mean, how recent?"

\section{Incomplete Information}

Some participants articulated correct information about newborn screening but were missing some general facts about the process and the purpose for this testing. Specifically, individuals correctly believed sickle cell, cystic fibrosis, and phenylketonuria are screened for in the newborn period. However, none of these individuals identified that newborn screening is a heel-stick blood test performed in the first days of life in order to detect or alter the outcome of a disease.

\section{Misinformation}

Several participants indicated blood type, heart murmur, diabetes, prenatal drug exposure, jaundice, and asthma are conditions tested for by newborn screening.

\section{Sub-Topic: Benefits of Newborn Screening}

After the moderator shared a common definition for newborn screening, participants identified potential benefits of treatment including themes of preparation and treatment.

\section{Preparation}

Individuals expressed a desire to have the information gathered from newborn screening to prepare to care for the child in an appropriate way. One mother discussed the importance of knowing her child had glucose-6-phosphate deficiency or G6PD in order to protect him from substances which could aggravate his condition.

I adopted my son, and when he was an infant, he had G6PD; something I knew nothing about. So it was good to know that and to have that information from the hospital. I know what not to have around him, 
what not to give him especially like aspirin, and no mothballs around him. Because my mom is from the "old school," she used to have mothballs, so I was real glad that I knew.

Another participant focused on the value of knowledge and the sense of security from being aware of a child's genetic condition. "You need to know what to look for. If it's there, if something happens, you need to know what you're dealing with (Female)." There were also participants who valued advance knowledge to prepare the appropriate services for a child in order to maximize his/her potential. For example, "I think to get as much early intervention as possible to help the child in ways that the child could be stimulated (Female)."

\section{Treatment}

The possibility for early treatment when a condition is identified by newborn screening was also explored by participant discussion. "I know you can test for a lot of conditions that can be treated within the first 3 months [of life]. You can give medication to the baby to be okay (Female)." The theme of early treatment to improve the outcome for a child with a serious condition is also evident in the following comment:

...And with cystic fibrosis at least they can start a plan of treatment so the child can have a productive or as much of a productive life as possible, as opposed to finding out when they're older, and you're starting from scratch when you could have prevented something. It's the same thing for a child that is diagnosed with autism. If it's further down the road, then you're behind the eight ball. Whereas if you find out early enough, you can start doing things to help get the child in the right direction and get them into the mainstream. (Female)

\section{Topic: Attitudes and Beliefs about Sickle Cell}

For each of the sub-topics under the general topic of knowledge of SCD, the theme of reliance on personal experiences was pervasive. Included under each sub-topic is a description of how this theme was demonstrated.

\section{Sub-Topic: Understanding of Symptoms}

Participants referred to watching an acquaintance, family member, or friend living with SCD or SCT when describing features of the condition. One woman described what she has learned about pain crises from talking with a co-worker:

I have a friend, she is a co-worker, and she has a daughter who has it. She has a son, but he doesn't have it. Her daughter has had it since birth, and what I've noticed is it seems like the older she is getting, the more she has episodes or crisis. It's painful. Her mother tells me she can't even get out to walk, and she's only 13 years old. She has had bouts in the hospital. They have to put her on morphine, so you can imagine with a little body like hers, it affects her psychologically.

Another spoke about the pain he witnessed when a family member went into a crisis stating, "I do know it's very painful because he used to ball up and just fall on the floor, and he'd be in a ball crying." One participant who was a junior high school teacher described her interaction with a student diagnosed with SCD.

If you've ever watched a child suffer from sickle cell, I had a student who had sickle cell. I was her teacher. It broke my heart to watch her sit in my classroom and the pain that she suffered, and to know she suffered all her life and even sadder, she knew she was never going to see 50 the way her health was.

\section{Sub-Topic: Difference between Disease and Trait}

In addition to articulating an understanding of SCD, several focus group participants were able to identify the cause of symptoms and the differences between disease and trait. Some were able to connect the name of the condition to the abnormal shape of the cell. Statements included "... From what I understand, it's like your cells are an abnormal shape (Male)" and "The shape of the cell is like a moon or crescent, and it stops the flow of the blood (Female)." Participants distinguished SCD from SCT by the presence or absence of symptoms and again relied on personal experience to make this distinction.

I had a friend who had sickle cell, and she would go into a crisis quite a bit. She didn't survive. She passed away in her early 30 s, and in her family there were a number of people who had the trait, and when you asked the question, the main thing I thought of was the trait doesn't go into crisis situation. (Female)

\section{Sub-Topic: Inheritance}

Uncertainty and misconceptions emerged as participants attempted to make sense of the pattern of disease and trait seen within a family. Some individuals questioned why only some children have disease when each parent has trait.

You would think, at least I do, if the mother or the father or both have it, then all the siblings would have 
it. Why is it maybe just one out of three or four may have it and the other ones not? (Male)

Other participants were uncertain as to why SCD would appear for the first time in a family.

My grandson's cousin was the first in our family. I mean it was a surprise to me that his first cousin was born with sickle cell and then later on, my grandson, my daughter's son, has a trace of sickle cell. So I don't know where that came from. It was surprising to me that he has the trait. I am clueless as to whether he received that from his father, because I know of no one on my side of the family that ever had that that I am aware of. (Female)

One woman observed a pattern in her family where only females had SCT. "I have the sickle cell trait, and when you were talking about different family members that have it, it seems like the females in my family have it. I had the trait, my daughter, my sister." Participants did not articulate what they believe the chances are to have a child with SCD when each parent has trait, nor did they discuss the chance for a child to inherit SCT when one or both parents have trait.

\section{Sub-Topic: Social Issues}

Participants commented on intimate knowledge of tension and stress within a family caring for a child with SCD.

I watch my friend. I ache for her because unfortunately we both work for a major corporation-I won't mention-but the area she works in they don't show sympathy for the time she needs to be off when her daughter is in the hospital, and she'll spend the night at the hospital and she'll go to work. Her husband has the type of job that he can adjust his schedule a little bit, so he'll be there during the day while she goes to work, and she goes home, washes up, goes to the hospital, spends the night at the hospital, gets up, and goes to work. (Female)

Another participant focused on the helplessness a family feels when a child with SCD is in pain.

...And the drain it takes on family members as parents to know something is wrong with your child and you're helpless, and what I see my girlfriend go through at times, there is nothing she can do to ease the pain and discomfort. (Female)

Other social issues that were addressed by participants' conversations focused on the stress an individual with SCD may experience as he/she interacts with the health care profession. A woman described the difficulty an adult may have acquiring pain medication from a skeptical physician in order to treat his/her SCD.

Sometimes the medical profession is not very sympathetic, and they think the young people want the drug and there is really no pain. So there are a whole lot of things that are going on. They think you just want some morphine drip. Come on! You want to be out doing things you want to do and being active just like your other friends, but because you are in the hospital and they can't pin point the pain. It's almost like back pain. You can't really pin point it.

Topic: Barriers to Education and Awareness of Sickle Cell Disease

Sub-Topic: Personal Barriers

\section{Avoidance}

A woman expressed a common sentiment repeatedly heard during each focus group. "Sometimes people don't want to know. They like to stay ignorant to the fact. If I don't know it, then it can't hurt me." A male participant stated:

I believe in not worrying about something. If you start thinking about these different diseases coming your way, sooner or later it's going to smack you right in the face. I don't deal with it. When it happens, it happens.

The desire to not consider the possibility of a disease is not unique to sickle cell. One participant described her experience with relatives who did not want to acknowledge the risk for polycystic kidney disease in the family.

I have to be real strong even with the rest of the family. This is something I have to do. I have brothers and a sister. 'I don't want to know. I don't want to know.' But like I said, I want to save my grandchildren. I am trying to protect my grandchildren. I was trying to protect my children. It was not something that I went into. I was forced into it.

Some participants described having an accurate knowledge of the risk for a particular disease in the family but openly denied its impact on their personal health. "Even those things that the family has experienced, I don't worry just because they experienced them. It doesn't mean my family or I am going to experience it." Another participant states:

Sometimes we take on different things that we hear and we accept, and sometimes the doctors will impart things and make you believe that you are going to 
have this. No, I am not going to have this, and I am not accepting what you are saying, and I am not going to receive it. My grandmother had that, and yes my mother had that, but that does not mean I am going to have that. Now you may want me to have this, but I am giving this back to you. I am not having cancer. I am not accepting diabetes, and I am not claiming it from this point on, so I am giving it back to you. (Female)

\section{Overwhelming Responsibilities}

For young mothers, there was a sense that other daily challenges take precedence over thinking about newborn screening for SCD and SCT.

I believe a lot of our people have other things to worry about besides whether my kid has sickle cell. There are other issues like whether they are going to have food on the table or whether their mother is a drug addict. A lot of these kids are out there. They are raising themselves because their parents are drug addicts. They have other issues that are more important to them than this. (Female)

\section{Sub-Topic: Family Barriers}

\section{Absence of Open Communication About Health Issues}

The absence of open communication about familial risk for disease was identified as a barrier to health awareness and education.

I'll give you an example. My dad is 82 . I just found out about a year ago that my dad is the oldest brother out of 6 siblings. My cousin is doing a family history, so he called. He is a radio announcer in Baltimore. He said 'I'm going to do a family history and ask everybody what school they went to, who they married, and so forth.' So I asked my dad. He said, 'Well you know one of my brothers has diabetes and my other brother has this, and my sister has this, but don't tell them I told you so.' What I am saying is if his brothers and sisters have these illnesses and he doesn't want me to know, how are their children supposed to know? How is this going to go down from generation to generation? (Female)

Participants were aware that a lack of family discussion about risk for disease prevents future generations from making informed decisions about their health. A participant shared the following, "I think a lot of times most families don't sit together to talk about family history, and those things pass down from generation from ancestors, and so once you learn your family history, then you can have a better picture (Female)."

\section{Shame}

The shame and stigma of disease within a family was identified as a hindrance to knowledge and prevention. "I think more families are talking more about it. It's not seen as you have to be ashamed about it (Female)."

Sub-Topic: Societal Barriers

\section{Distrust}

Participants described a lack of trust in the medical establishment due to past abuses directed against AfricanAmericans. Participants discussed the Tuskegee Syphilis Study. As one participant said, "Like the Tuskegee experiments, our parents pass that on to their children and grandchildren. That is don't trust the police, don't trust the medical [profession]. That is passed on (Female)." This distrust and fear was also evidenced in young focus group participants. One young woman stated:

I am praying on it because it is really crazy the way they use black people for experimentation and then they don't teach you a doggone thing in the schools about what is going on and it probably has to occur with the people...start speaking up and saying something.

\section{Minimal Media Attention}

Participants explained the belief that there is not enough SCD activism and health education within the community and that leads to minimal media attention on the condition.

I remember in the 80 's it was on billboards. That was the first time I had heard about it. I came back here from some place else and it was on billboards. They had some celebrities on TV talking about it. Then after the 80's, you don't hear about it anymore. (Females)

Participants believe that other public health issues such as HIV/AIDS are given more media attention within the community.

It's [sickle cell] a disease that affects mostly African Americans and then I'll bring this up. AIDS affects everyone. Every day, every time you can see radio, print, TV about AIDS and HIV 'Get tested.' How 
come nobody is out in the communities saying to African Americans put it [sickle cell] on TV. It doesn't matter whether it affects Caucasians or Mexicans or whoever. Why isn't it out there? Like I said, I didn't know about it until I was 30 something years old. (Female)

\section{Minimal Physician Discussion}

Participants believe that a lack of awareness also stems from physicians not providing the necessary information about sickle cell. Throughout the conversations, participants expressed their frustration with their lack of knowledge and felt that their physician should have supplied the information regardless of whether or not the patient asked about SCT testing.

You go in the doctor's office waiting for him. You see 'If you have diabetes, take your shoes and socks off.' You see mammograms. You see all these different things on the wall. There are flu shots. I don't see anything about sickle cell. I don't see anything about lupus. I see more about stem cell research which I have no clue really what it is but I see a lot of it and bone marrow transplants for African Americans because that is so rare. If it only affects a certain group of individuals, be it minorities, then it seems like there is not a lot of information out there and they [physicians] don't care. (Female)

\section{Lack of Knowledge Among Teenage Mothers}

Participants felt that teenage mothers were unaware of the risk for SCD.

Mothers are not physicians and so you can't expect them to be informed and know what questions to ask and so I think if you are a professional, a concerned physician, then you will supply that kind of information to them and particularly young mothers. Girls are having babies at 11 and 12, 15, 18 years old and they don't have any questions to ask. They don't know and so it's the responsibility of the physician. (Female)

I think also with mothers being so young today they are not aware. What do they know about sickle cell? Adults don't know about it. With the age of the mothers being so young, they don't know and a lot of times the doctors take advantage of that, and they may just mention it, but it will blow over. This is a young mother. She is probably concerned about how she is going to take care of this child-fearful and fright- ened. So a doctor probably knows that, but that parent doesn't really focus on that. (Female)

\section{Discussion}

Research among African-Americans indicates this population perceives SCD to be a serious disease and SCT screening an important intervention. However, studies have consistently demonstrated a lower than desired uptake of SCD education, inadequate knowledge regarding personal and family trait status, and a low perceived susceptibility of giving birth to a child with the disease (Acharya et al. 2009; Gustafson et al. 2007; Kladny et al. 2005; Midence et al. 1994; Treadwell et al. 2006; Wright et al. 1994). In this study, we examined general attitudes and beliefs regarding genetics and genetic testing including prenatal testing and newborn screening among a unique sample of AfricanAmerican adults; we used this information as the foundation to more specifically assess attitudes and beliefs regarding $\mathrm{SCD}$ and perceived barriers to $\mathrm{SCD}$ education and awareness.

This study took a qualitative thematic approach to provide a deeper understanding of why AfricanAmericans perceive SCD to be a serious disease but have a low perceived susceptibility to have a future child with SCD and lower than desired awareness and uptake of SCD education. As stated previously, past experiences, beliefs, and attitudes influence the way individuals approach new knowledge, learning, and decisionmaking (Catz et al. 2005). By discerning attitudes and beliefs about genetics and common genetic testing scenarios among a unique sample of African-Americans, we were able to then integrate this information into our understanding of participants' attitudes and beliefs toward SCD and perceived barriers to SCD education and awareness.

Attitudes and Beliefs Regarding Prenatal Testing and Newborn Screening

Both prenatal testing and newborn screening were generally viewed as acceptable forms of genetic testing by focus group participants. Although with prenatal testing both concerns and potential risks were raised, the overall response was that there is a significant benefit to having information. Participants described how this form of testing allows one to be aware of issues for a future child and make informed choices about continuing or terminating a pregnancy. As evidenced by participants' responses, termination is an acceptable choice in situations that involve a medical issue affecting the fetus. 
Prenatal testing was a relatively familiar concept for the majority of focus group participants. They drew from and cited their own personal experiences or those of friends and family members. Newborn screening was a much less familiar form of testing. Participants fell into one of three knowledge categories when discussing newborn screening: those who were unaware, those who had accurate but incomplete knowledge, and those who had misinformation. After a definition of newborn screening was provided by the moderator, conversational flow about this form of testing occurred. Very few participants cited personal or second-hand experiences with newborn screening or its outcome. Interestingly, newborn screening was viewed as only beneficial; participants identified no risks or concerns regarding obtaining this type of genetic knowledge. This may be due to participants' less familiarity with newborn screening when compared to prenatal testing.

The general positive acknowledgement and noted benefits of prenatal testing and newborn screening and the acceptance of termination in a situation where a medical issue is affecting the fetus are noteworthy. These findings make it less likely that negative attitudes and beliefs about genetic testing or the potential outcome of genetic testing (termination) are influencing the lower than desired uptake of SCD education, inadequate knowledge regarding personal and family trait status, and low perceived susceptibility of giving birth to a child with the disease. It should be emphasized, however, that qualitative data are not intended to be generalized to the population of interest. Therefore, such conclusions are tentative.

\section{Reliance on Experience}

When discussing the resources participants access for information about genetics, very few individuals spoke of seeking out information from the library, books, or internet resources. Similarly, a quantitative study by Nicholson and colleagues (2003) examining the relationship between race and women's use of health information resources found that African-American women had 50-70\% less odds of using print news media, computer resources, or health organizations for information when compared to Caucasian women. In the current study, focus group participants reported relying on what they knew from on the job experience, participation in research studies, stories they had witnessed on television, and discussions with physicians, family, and friends. Prior research on the information seeking behaviors of African-Americans has similarly demonstrated the importance of personal sources such as family, friends, and the church (Acharya et al. 2009; Nicholson et al. 2003; Talosig-Garcia and Davis 2005).

As participants discussed complicated issues such as genetic disease and genetic testing in the prenatal period, their reliance on personal or secondhand experiences appeared to help them to have a more robust understanding of the potential benefits and risks or concerns regarding prenatal testing. Their greater exposure to prenatal testing and the stories of friends and family members seemed to give them more confidence in their knowledge of the topic and their knowledge was often accurate.

When discussing newborn screening, participants cited fewer personal or secondhand stories. Their knowledge and accuracy concerning this topic were also reduced in comparison to prenatal testing. However, once given information on newborn screening, participants conversed about the potential benefits of this form of testing.

Throughout focus group discussion it was clear participants possessed an appropriate understanding of the severity of SCD symptoms and clinical course but in general were unaware or misinformed about the inheritance of the condition. Similar to previous research, individuals accurately identified that SCT and SCD travel through families but did not understand the risk to children conceived by parents when one or both have SCT (Acharya et al. 2009; Gustafson et al. 2007; Treadwell et al. 2006).

In the current study, it was noted that reliance on personal experiences with family and friends had a negative impact on the understanding of the inheritance of sickle cell for some participants. By concentrating on the experiences of one situation, individuals misinterpreted the inheritance of SCD which led to inaccurate risk perception. This could be a factor contributing to African-Americans' low perceived susceptibility to have a child with SCD.

\section{Knowledge of Sickle Cell Trait Status}

Similar to previous research, the current study found that a majority of focus group participants did not know their personal SCT status or that of their spouse/partner and children (Midence et al. 1994; Wright et al. 1994). Fortytwo percent of the 35 participants knew their personal SCT status. This percentage was higher than expected, but given that $97 \%$ of participants had health insurance and only $17 \%$ had difficulty seeing a physician due to cost, individuals may have had greater interaction with the medical profession and access to testing for SCT. This larger than expected percentage may also be due to participants' age. The majority experienced their childbearing years during the early 1970s which is the time period when federal funding for state sickle cell screening programs was available (Markel 2006).

Interestingly, the majority of focus group participants did not know the SCT status of their spouse or partner. This finding may be in part reflective of the theme which emerged from focus group discussion regarding the lack of family communication about health conditions. However, 
partners may not have had testing in order to know their status. Additionally, the majority of participants did not know their child's SCT status. This finding may be rooted in the fact that many participants are past their childbearing years, and newborn screening for sickle cell did not become mandatory in Pennsylvania until 1990 (Olney 2000). As participants indicated throughout focus group discussions, parents of older children may not have known to ask their physician to perform SCT screening due to a lack of awareness of the risk for the condition. Additionally, family physicians may not have explained the importance of SCT screening to their African-American patients or inquired about the results of newborn screening for sickle cell.

\section{Barriers to Sickle Cell Disease Education and Awareness}

Participants identified specific personal, familial, and societal barriers to awareness that are at work in their daily family and community lives. The societal barrier described as distrust of the medical profession due to past abuses is an issue deeply rooted in African-American culture. A similar theme was reported in focus groups conducted by Treadwell and colleagues (2006) as well as Zimmerman and colleagues (2006). Additionally, a qualitative study of African-American community members' attitudes toward medical research found that the Tuskegee syphilis study was an important negative factor in the decision to participate in research for older individuals, while distrust of physicians was a personal barrier for both younger and older participants (Hamilton et al. 2006).

Participants also feared acknowledging the risk for a health condition such as sickle cell to occur, resulting in their use of coping mechanisms such as avoidance and denial. Several individuals reported believing that simply thinking about a risk would cause the disease to develop in themselves or a family member. This was an interesting finding considering that participants possessed a high level of education in comparison to the larger African American community from which they were drawn.

African-Americans' denial of multifactorial health conditions has been documented in the literature as well. Specifically, denial has been associated with diseases which have a significant racial health disparity such as prostate cancer, heart disease, breast cancer, and stroke (Gullate 2006; King et al. 2001; Richardson et al. 2004; Rucker-Whitaker et al. 2006). These studies have identified anxiety and repression of fear as potential causes of African-Americans denying their risk for disease (Gullate 2006; King et al. 2001; Richardson et al. 2004; Rucker-Whitaker et al. 2006). A study by Gullate (2006) documented this denial as "If you name it, you claim it." This complex sentiment is similar to the thoughts expressed in the present focus groups. The explanation for this belief is difficult to encapsulate and attribute simply to denial or avoidance. It is likely more nuanced than this. From a cultural perspective, this belief might be viewed as a complicated use of self-justification to express optimism that one can cope and/or overcome a challenging health situation.

The barriers of fear, denial, and a societal/cultural lack of awareness may be connected to the absence of open communication about health issues within some AfricanAmerican families. Participants stated they were limited in their knowledge of family disease risk because older generations did not want to discuss a personal or family history of health conditions, and issues of personal and family shame prevented relatives from discussing their own health issues. Participants also brought attention to the lack of family conversation about SCT status and family history of SCD. They believe that the absence of discussion causes future generations to have misconceptions about sickle cell that can lead them to fear and deny their family history. The absence of family communication about sickle cell may also be a factor in the lack of knowledge among teenage parents. If parents do not talk with their children about SCT status and the risk for disease, then a lack of awareness may be perpetuated into the next generation.

\section{Study Limitations}

The study is limited by the method of recruitment and sampling of African-American community members. Individuals who participated in this research project were selfselected and many spoke of the importance of giving back to the HBFP by contributing their time to research. The majority of participants were recruited from the MRRD and therefore, already inclined to participate in research. This was a unique sample of the African-American population. Moreover, as mentioned previously, qualitative data are not intended to be generalized to the larger African American population.

The vast majority of the sample were female, which is consistent with the larger HBFP population. The under representation of African American men within the HBFP is not uncommon for other health and wellness programs. Women are consistently the early adopters of medical and health related information. Studies examining the barriers to African-Americans' participation in research have demonstrated that men and women differ in the types of barriers described and the impact those barriers have on participation (BeLue et al. 2006; Hoyo et al. 2003). Specifically, African-American men participating in qualitative studies have been found to be concerned about the costs and time commitment of research participation (BeLue et al. 2006; Hoyo et al. 2003). Additionally, men have been found to have a low interest level and participation rate in research because of a lack of knowledge and awareness about the 
process of research (Hoyo et al. 2003). In contrast, AfricanAmerican females have described barriers such as the researcher-participant relationship and the need to have the researcher make the participant feel comfortable (BeLue et al. 2006). Women may have felt more comfortable than men attending the focus groups because they had previously met with the moderator and assistant to the moderator through other HBFP events, and they were familiar with the Kingsley Association, which also has services and targeted programming for school aged children.

The median age of focus group participants was beyond the typical reproductive years. Though discussion of topics such as newborn screening and prenatal testing may be more appropriate for individuals of childbearing age, the overall goals of the project were attained by capturing the opinions of diverse members of the community. It is also important to point out that as evidenced by group conversation SCD pervades community life regardless of age. Many of the older focus group participants were primary caretakers for grandchildren and had intimate knowledge of prenatal testing, newborn screening, and sickle cell.

Participant income levels were representative of the area when compared to data collected by the US Census in conjunction with information compiled by the University of Pittsburgh RCEMHD and the Allegheny County Health Department (Robins 2005). In the current study, all participants completed high school with the majority completing post-high school education which is greater than the educational level previously described in this community (Robins 2005). Although there was a difference in educational background between focus group participants and those living in the larger community, this study was able to demonstrate that a sample of African-American individuals with a high level of education have both inaccurate and incomplete information about newborn screening and sickle cell inheritance and risk. Therefore, one could speculate that a sample of individuals with less advanced education would have less accurate knowledge of these topics.

\section{Practice Implications}

The results of this study highlight the importance of identifying trusted sources of information within the African-American community when designing strategies to address barriers to SCD education and awareness. Locating and establishing relationships with these trusted sources is one potential approach that would allow genetic counselors in the clinical and community outreach settings the opportunity to formulate partnerships to promote SCD education. As noted by this study and others, community physicians, community leaders with an association to a medical or health profession, and the church are often identified as trusted sources. Collaborating with these sources to promote or host educational events and distribute print and internet based materials creates the opportunity to increase the trust and rapport which have already been established between the community and trusted sources.

Community based events hosted by an identified neighborhood health center, church, or other trusted community organization could focus on providing active learning. The goal of this design would be to allow participants the opportunity to come together and learn in a familiar community environment and gain insights and experiences from an interactive program. Guest speakers could include families who have a child with SCD and physicians or genetic counselors involved in sickle cell screening or caring for individuals with SCD. The personal story of a family or individual with sickle cell would provide participants with the experience and observation to draw on as they attempt to understand the condition and explain it to other family members and friends. At the same time, a physician and/or genetic counselor can draw attention to specific aspects of the patient or family's story and clarify issues regarding inheritance, testing, and screening.

Genetic counselors in the clinical setting may also find utility in identifying their clients' trusted sources of information and personal experiences with SCD and SCT. When SCD and/or SCT is mentioned in the reporting of the family history or when the patient or partner's ethnic background is consistent with an increased risk of SCT, the disease, inheritance and risk, and testing should be addressed. However, before providing a description of the autosomal recessive inheritance pattern of this condition, we would suggest first asking the client, couple, or family how they believe sickle cell is inherited and then asking why they believe this pattern exists. The answers may provide useful opportunities to address misinterpretations of disease inheritance and validate those responses which accurately describe risk. This conversation may also invite discussion of barriers to SCT testing for the client and partner and allow the genetic counselor the opportunity to gather insight into the client's belief system and coping mechanisms and to identify individualized strategies for recognizing and overcoming these barriers.

One particularly noteworthy barrier in the current study was the lack of familial communication about health issues. Identification of this barrier presents an opportunity for genetic counselors to play an important role in facilitating and enhancing family discussions. Genetic counselors could use a variety of strategies to help diminish this communication barrier such as offering to meet with 
multiple members of a family, composing family letters, providing tools to create a family health history, and partnering with trusted community sources to promote family discussion.

\section{Research Recommendations}

This study did not explicitly assess whether focus group participants had any previous experiences with genetic counseling for sickle cell in the preconception, prenatal, or pediatric setting. Future research studies could examine and compare the knowledge and understanding of the differences between SCD and SCT and risk perception among individuals who have undergone genetic counseling in one or more of these settings in order to determine the most effective method or combination of methods for providing education and the extent to which that information was used in reproductive decision making.

Additionally, if a community education intervention could be designed and implemented, the effectiveness of this intervention would merit investigation. It would be of interest to determine individuals' motivations for participating in the intervention, whether the information is retained at various time points, the accuracy of the information retained, whether or not the information was shared with children, partners, family, and friends, and if the information was utilized by the participants in reproductive decision making.

Acknowledgements This study was completed in partial fulfillment of the requirements for the first author's Master of Science degree from the University of Pittsburgh. We are grateful for the financial resources to complete this project provided by the University of Pittsburgh Center for Minority Health, NIH National Institute on Minority Health and Health Disparities (PG60MD000207; S. Thomas, PI), and the Sickle Cell Program at Children's Hospital of Pittsburgh.

\section{Appendix}

We thank you for participating in this focus group. This survey is to gather information about the community's interactions with genetics, genetic testing, and sickle cell. If there is a question that you do not feel comfortable answering, you can skip it and continue on. Please answer the following questions to the best of your ability. The survey should take approximately 10 minutes. We would like to thank you in advance for your willingness to participate in this study.

\section{Section 1: General Information}

1) What is your age?

$$
\ldots \text { age in years }
$$

2) What is your gender?

1 Male

2 Female

3) Are you Hispanic or Latino?
1 Yes
2 No
3 Don't know

3a) Which one or more of the following would you say is your race? (Check all that apply)
1 White
2 Black or African American
3 Asian
4 Native Hawaiian or Other Pacific Islander
5 American Indian, Alaska Native
6 Other [specify]

4) What was the total household income from all sources last year?

1 Less than $\$ 10,000$

2 Between $\$ 10,000$ and $\$ 20,000$

3 Between $\$ 20,001$ and $\$ 35,000$

4 Between $\$ 35,001$ and $\$ 50,000$

5 Between $\$ 50,001$ and $\$ 75,000$

6 Greater than $\$ 75,000$

5) What is the highest grade or year of school you completed?

1 Grades 8 or less (Elementary)

2 Grades 9 through 11 (Some high school)

3 Grade 12 or GED (High school graduate)

4 College 1 year to 3 years (Some college or technical school)

5 College 4 years or more (College graduate or postgraduate)

6 Graduate level (Masters or $\mathrm{PhD}$ )

6) How would you rate your knowledge on genetics?
1 Excellent
2 Very good
3 Good
4 Fair
5 Poor

7) How would you describe your general health?

1 Excellent

2 Very good

3 Good

4 Fair

5 Poor 
8) Do you smoke?

1 Yes

2 No

9) How would you describe your weight?

$\begin{array}{ll}1 & \text { Underweight } \\ 2 & \text { Healthy weight } \\ 3 & \text { Overweight } \\ 4 & \text { Obese }\end{array}$

10) Do you have one person you think of as your personal doctor or health care provider?

1 Yes, only one

2 More than one

3 No

4 Don't know / Not sure

11) Was there a time in the past 12 months when you needed to see a doctor but could not because of the cost?

11 Yes

2 No

3 Don't know / Not sure

12) Do you have any kind of health care coverage, including health insurance, prepaid plans such as HMOs, or government plans such as Medicare?
1 Yes
2 No
3 Don’t know / Not sure

Section 2: Sickle Cell and Newborn Screening

13) Do you know your sickle cell trait status?
1 Yes
2 No
3 Don't know

14) Do you know your partner/spouse's sickle cell trait status?
1 Yes
2 No
3 Don't know
4 Not applicable

15) Do you have children?
1 Yes
2 No

16) If you answered "Yes" to the previous question, do you know your child's sickle cell trait status?
1 Yes
2 No
3 Don't know

17) Do you know someone with sickle cell disease?
1 Yes
2 No
3 Don't know

18) Do you know someone with sickle cell trait?
1 Yes
2 No
3 Don't know

19) Do you know someone that was found to have sickle cell disease or trait by newborn screening?
1 Yes
2 No
3 Don't know

\section{Focus Group Guide}

I. Introduction (10 $\mathrm{min})$

Good afternoon/evening and welcome to our session. Thank you for taking the time to join our discussion on genetics, genetic testing, and sickle cell. My name is and I am with the Healthy Black Family Project from the Center for Minority Health at the University of Pittsburgh. Assisting me is who will be taking notes on the conversation during the focus group. Please begin by filling out the survey in front of you by circling your answers. We will begin when everyone has completed this form.

You have been invited because you are a member of the Healthy Black Family Project and your opinions on genetics, genetic testing, and sickle cell are important to us. Our research team is trying to understand the attitudes and beliefs of African-Americans toward these issues. We would like to hear your opinions. We will ask you a number of questions and we need your honest thoughts and ideas. Please feel free to share your point of view especially if it is different from what others have said. There are no wrong answers, only different points of view.

Now, let me share some ground rules. We want to make sure that everyone feels comfortable expressing his or her own opinion. We ask that you are respectful of everyone by listening to one another and waiting until the person speaking has finished before you begin. Please do not have side conversations with your neighbor during the discussion. All of your comments are helpful and would provide us with useful information. We have placed cards on the table in front of you to help us remember your names during the focus group.

As you have probably noticed, we have a microphone on the table. We will be tape recording our discussion so 
that we don't miss any of your comments. To assure you of your confidentiality, we will only be using the names you selected for today and will not use any names in our final reports.

The group discussion will last about 2 hours so please feel free to enjoy your meal as we begin. We will have a 10-minute break. You should have already completed the brief survey and we will collect it before we begin.

II. Assessing Knowledge of Genetics Question 1

Where do you receive trusted medical information?

Probe: From a Physician, Nurse, Pharmacist, Friend/Family member, TV, radio, newspaper, internet, seminar, etc.?

Probe: Why is this your most trusted source of medical information?

\section{Question 2}

What comes to mind when you hear the word "genetic" or "genetics"?

Probe: Where have you heard this word? Who has used the word?

Probe: How do you think "things" are passed down to or inherited from one generation to another? Why?

III. Assessing Knowledge of Prenatal Testing and Newborn Screening for Genetic Conditions Question 3

When you hear the words "prenatal testing" what does it mean to you?

[Definition shared if no one answers: Prenatal testing is testing performed on the developing baby while a woman is pregnant. It can be used to gather information about genetic health conditions in the baby.]

Probe: Are there benefits of prenatal testing? What are these benefits? Why?

Probe: Are there risks of prenatal testing? What are these risks? Why?

Probe: Would you want to know if your baby had a genetic condition?

Question 4

When you hear the phrase "newborn screening" what do you think of?

Probe: This is also referred to as the "heel stick test."

[Definition shared if no one answers: Newborn screening is testing performed on the newborn baby before leaving the hospital. A small sample of blood is obtained from the baby's heel to test for rare genetic diseases that are life-threatening but where early intervention or treatment has an impact on disease outcome.]

Probe: Where have you heard the phrase used?

Probe: Who has used it?

Probe: Under what conditions or circumstances has it been used?

Probe: What kind of information would you like to know before a child's blood is taken?

Probe: Are there benefits of newborn screening? What are these benefits? Why?

Probe: Are there risks of newborn screening? What are these risks? Why?

Probe: Would you want to know if your child had a genetic condition?

IV. Assessing Understanding of Sickle Cell Disease Question 5

What is sickle cell disease?

Probe: Where have you heard this condition discussed?

Probe: What is the difference between the sickle cell disease and sickle cell trait?

Probe: Do you think one is more serious than the other? Why?

Probe: How does someone get sickle cell?

V. Assessing Perceived Risk of Sickle Cell Question 6

Earlier we talked about how things are inherited or genetics, do you think there is a risk in your family to have a future child or grandchild with sickle cell trait? Do you think there is a risk in your family to have a future child or grandchild with sickle cell disease?

Probe: Why or why not?

VI. Assessing Opinions on Sickle Cell and Newborn Screening

Question 7

Scenario: It is three days after the birth of your child and you just found out your child has sickle cell disease. How helpful would this information be to you? If your child had sickle cell trait, how helpful would this information be to you?

Probe: What would you do with this information?

VII. Assessing Ideas on Community Education Interventions Question 8

How can the community help parents become more aware of information about sickle cell? 
VIII. Closing

Thank you for your time and energy given to this discussion. It was a pleasure listening to your thoughts and opinions. We will need your signature to indicate you have received your $\$ 25$ gift certificate before you leave.

\section{References}

Acharya, K., Lang, C. W., \& Ross, L. F. (2009). A pilot study to explore knowledge, attitudes, and beliefs about sickle cell trait and disease. Journal of the National Medical Association, 101, $1163-1172$.

Beeson, D. (1997). Nuance, complexity, and context: qualitative methods in genetic counseling research. Journal of Genetic Counseling, 6, 21-43.

BeLue, R., Taylor-Richardson, K. D., Lin, J., Rivera, A. T., \& Grandison, D. (2006). African Americans and participation in clinical trials: differences in beliefs and attitudes by gender. Contemporary Clinical Trials, 27, 498-505.

Braun, V., \& Clarke, V. (2006). Using thematic analysis in psychology. Qualitative Research in Psychology, 3, 77-101.

Catz, D. S., Green, N. S., Tobin, J. N., Lloyd-Puryear, M. A., Kyler, P., Umemoto, A., et al. (2005). Attitudes about genetics in underserved, culturally diverse populations. Community Genetics, $8,161-172$.

Gullate, M. (2006). The influence of spirituality and religiosity on breast cancer screening delay in African American women: application of the Theory of Reasoned Action and Planned Behavior (TRA/TPB). Journal of the Association of Black Nursing Faculty in Higher Education, 17, 89-94.

Gustafson, S. L., Gettig, E. A., Watt-Morse, M., \& Krishnamurti, L. (2007). Health beliefs among African American women regarding genetic testing and counseling for sickle cell disease. Genetics in Medicine, 9, 303-310.

Hamilton, L. A., Aliyu, M. H., Lyons, P. D., May, R., Swanson, C. L., Savage, R., et al. (2006). African-American community attitudes and perceptions toward schizophrenia and medical research: an exploratory study. Journal of the National Medical Association, 98, 18-27.

Hoyo, C., Reid, M. L., Godley, P. A., Parrish, T., Smith, L., \& Gammon, M. (2003). Barriers and strategies for sustained participation of African-American men in cohort studies. Ethnicity \& Disease, 13, 470-476.

Janz, N. K., \& Becker, M. H. (1984). The health belief model: a decade later. Health Education Quarterly, 11, 1-47.

Kass, N. E., Medley, A. M., Natowicz, M. R., Hull, S. C., Faden, R. R., Plantinga, L., et al. (2007). Access to health insurance: experiences and attitudes of those with genetic versus nongenetic medical conditions. American Journal of Medical Genetics. Part A, 143, 707-717.

Kessler, L., Collier, A., Brewster, K., Smith, C., Weathers, B., Wileyto, E. P., et al. (2005). Attitudes about genetic testing and genetic testing intentions in African American women at increased risk for hereditary breast cancer. Genetics in Medicine, 7, 230-238.

King, D. F., Trouth, A. J., \& Adams, A. O. (2001). Factors preventing African-Americans from seeking early intervention in the treatment of ischemic strokes. Journal of the National Medical Association, 93, 43-46.

Kladny, B., Gettig, E. A., \& Krishnamurti, L. (2005). Systematic follow-up and case management of the abnormal newborn screen can improve acceptance of genetic counseling for sickle cell or other hemoglobinopathy trait. Genetics in Medicine, 7, 139-142.

Krueger, R. A., \& Casey, M. A. (2000). Focus groups: A practical guide for applied research (3rd ed.). Thousand Oaks: Sage.

Laskey, S. L., Williams, J., Pierre-Louis, J., O’Riordan, M., Matthews, A., \& Robin, N. H. (2003). Attitudes of African American premedical students toward genetic testing and screening. Genetics in Medicine, 5, 49-54.

Markel, H. (2006). Scientific advances and social risks: Historical perspectives of genetic screening programs for sickle cell disease, Tay-Sachs disease, neural tube. National Human Genome Research Institute. Retrieved from http://www.genome.gov/ 10002401.

Midence, K., Graham, V., Acheampong, C., \& Okuyiga, E. (1994). Increasing awareness for higher quality care. Measuring knowledge of sickle cell disease in adult patients. Professional Nurse, 9, 255-258.

National Newborn Screening and Genetics Resource Center, National Newborn Screening Report, Sickle Carrier Program Follow-up (2009). Available at: http://nnsis.uthscsa.edu/xreports.aspx?XRE PORTID=22\&FORMID=8\&FCLR=1. Accessed January 8, 2011.

Nicholson, W. K., Grason, H. A., \& Powe, N. R. (2003). The relationship of race to women's use of health information resources. American Journal of Obstetrics and Gynecology, $188,580-585$.

Olney, R. (2000). Newborn screening for sickle cell disease: Public health impact and evaluation. Genetics and public health in the 21st century. Oxford University. Retrieved from http://www.cdc. gov/genomics/resources/books/21stcent/chap22.htm.

Pass, K. A., Lane, P. A., Fernhoff, P. M., Hinton, C. F., Panny, S. R., Parks, J. S., et al. (2000). US newborn screening system guidelines II: follow-up of children, diagnosis, management, and evaluation. Statement of the Council for Regional Networks for Genetic Services (CORN). Journal of Pediatrics, 137, S1-S46.

Richardson, J. T., Webster, J. D., \& Fields, N. J. (2004). Uncovering myths and transforming realities among low-SES African-American men: implications for reducing prostate cancer disparities. Journal of the National Medical Association, 96, 1295-1301.

Richer, J., \& Chudley, A. E. (2005). The hemoglobinopathies and malaria. Clinical Genetics, 68, 332-336.

Robins, A. G. (2005). Surveillance of selected chronic diseases: Benchmarks for the healthy Black Family Project. Allegheny Health Department and Center for Minority Health.

Rucker-Whitaker, C., Flynn, K. J., Kravitz, G., Eaton, C., Calvin, J. E., \& Powell, L. H. (2006). Understanding African-American participation in a behavioral intervention: results from focus groups. Contemporary Clinical Trials, 27, 274-286.

Sandelowski, M. (2000). Focus on research methods: whatever happened to qualitative description? Research in Nursing and Health, 23, 334-340.

Talosig-Garcia, M., \& Davis, S. W. (2005). Information-seeking behavior of minority breast cancer patients: an exploratory study. Journal of Health Communication, 10, 53-64.

The New York State Task Force on Life and the Law. (2000). Genetic testing and screening in the age of genomic medicine. New York: Author.

Thomas, S., \& Quinn, S. (2008). Poverty and the elimination of urban health disparities: challenge and opportunity. Annals of the New York Academy of Sciences, 1136, 111-125.

Treadwell, M. J., McClough, L., \& Vichinsky, E. (2006). Using qualitative and quantitative strategies to evaluate knowledge and perceptions about sickle cell disease and sickle cell trait. Journal of the National Medical Association, 98, 704-710.

US Census Bureau (2005). Poverty thresholds. Available at: http:// www.census.gov/hhes/www/poverty/data/threshld/thresh05.html. Accessed January 30, 2011. 
Vogel, K. J., Murthy, V. S., Dudley, B., Grubs, R. E., Gettig, E., Ford, A., et al. (2007). The use of family health histories to address health disparities in an African American community. Health Promotion Practice, 8, 350-357.

Wethers, D. L. (2000a). Sickle cell disease in childhood: part I. Laboratory diagnosis, pathophysiology, and health maintenance. American Family Physician, 62, 1013-1020.

Wethers, D. L. (2000b). Sickle cell disease in childhood: Part II. Diagnosis and treatment of major complications and recent advances in treatment. American Family Physician, 62, 1309-1314.
Wilson, R. E., Krishnamurti, L., \& Kamat, D. (2003). Management of sickle cell disease in primary care. Clinical Pediatrics, 42, 753-761.

Wright, S. W., Zeldin, M. H., Wrenn, K., \& Miller, O. (1994). Screening for sickle-cell trait in the emergency department. Journal of General Internal Medicine, 9, 421-424.

Zimmerman, R. K., Tabbarah, M., Nowalk, M. P., Raymund, M., Jewell, I. K., Wilson, S. A., et al. (2006). Racial differences in beliefs about genetic screening among patients at inner-city neighborhood health centers. Journal of the National Medical Association, 98, 370-377. 